\title{
O TERRITÓRIO NO ENSINO-APRENDIZAGEM DE GEOGRAFIA
}

\author{
The territory in the Geography teaching-learning process
}

\author{
Marcos Aurelio Saquet \\ Professor Associado $B$ da Unioeste \\ Grupo de Estudos Territoriais \\ saquetmarcos@hotmail.com
}

\section{Resumo}

O conceito de território tem assumido cada vez mais centralidade e relevância na Geografia brasileira, no ensino, na pesquisa e em projetos de desenvolvimento. Assim, há necessidade de conhecer como esse conceito é trabalhado, identificando concepções utilizadas, temas estudados, recortes (espacial e temporal) e possíveis imprecisões. Neste texto, analisamos como o território é concebido e utilizado numa coleção de livros didáticos de Geografia direcionada para o Ensino Fundamental do $1^{\circ}$. ao $4^{\circ}$. ano, mostrando qualidades dos livros e possibilidades para ampliar e aprofundar o estudo dos temas da ciência geográfica a partir de uma abordagem territorial histórico-crítica, relacional, reticular e múltipla. A pesquisa revelou que há qualidade na coleção analisada, porém, esta pode ser ainda melhor, conforme sugerimos no decorrer do texto.

Palavras-chave: território, Geografia, ensino, aprendizagem.

\section{Abstract}

The concept of territory has been taking more importance in the brazilian Geography, in the teaching, in the research and in projects of development. Thus, there is a need of knowing how such concept is developed, identifying used conceptions, studied topics, clippings (spatial and temporal) and possible inaccuracies. On this context, it has been analyzed how territory is conceived and used in a Geography text book collection targeted to elementary school from $1^{\circ}$ to $4^{\circ}$ degree, showing qualities of books and possibilities of broadening and deepening the study of topics of geographic science from a historic critical, relational, reticular and multiple territorial approach. The research revealed that there is quality in the collection examined, however, this may be even better, as suggested throughout the text.

Key-words: territory, Geography, education, learning.

$$
\begin{aligned}
& \text { “(...) ensinar não é transferir conhecimento, mas criar as possibilidades para a sua } \\
& \text { produção ou a sua construção” (FREIRE, 2011/1996, p. 24; grifos no original). } \\
& \text { “(...) onde quer que haja mulheres e homens há sempre o que fazer, há sempre o que } \\
& \text { ensinar, há sempre o que aprender” (Idem, p. 82). }
\end{aligned}
$$




\section{Apresentação}

Os conceitos de território e territorialidade, entendidos como tema de pesquisa e ensino-aprendizagem, têm cada vez mais centralidade e relevância na Geografia brasileira, nos ensinos fundamental, médio e superior. Isso é notório e pode ser facilmente comprovado. Assim, há necessidade de conhecer como esses conceitosprocessos-temas são trabalhados no ensino de Geografia, identificando concepções, temas correlatos, recortes (espacial e temporal), exercícios e possíveis imprecisões.

Em se tratando da difusão desses conceitos na ciência geográfica brasileira, a possibilidade de avaliação dos livros didáticos de Geografia por meio do Programa Nacional do Livro Didático (PNLD) oferece-nos uma ótima oportunidade para reflexão, neste caso, sobre o tema território-territorialidade no Ensino Fundamental do $1^{\mathrm{o}}$. ao $4^{\mathrm{o}}$. ano.

Para esta reflexão, escolhemos uma coleção como objeto principal, que orienta a organização e a redação deste texto: "Geografia PARATODOS" (SENE, CAVALCANTI e MOREIRA, 2004). Descreveremos e analisaremos como o território é tratado nesta coleção destinada ao ensino de Geografia, juntamente com outros temas, tecendo sugestões para a utilização do território e da territorialidade na prática didática do ensino-aprendizagem-ensino.

A abordagem territorial que estamos construindo, com base nos conceitos de território, territorialidade, tempo e temporalidade (SAQUET, 2003/2001, 2007, 2009 e 2011), sem desconsiderar o espaço geográfico, é de grande importância para estudos dos processos sociais e espaciais bem como para o ensino de Geografia em diferentes níveis escolares. Acreditamos que é uma maneira coerente para compreender e explicar atividades da nossa vida cotidiana e sua territorialização, evidenciando temas e processos como a degradação ambiental, as relações de poder (ordens, conflitos, contradições, normas, regras etc.), os processos e símbolos culturais, as redes de circulação e comunicação, a mobilidade populacional etc. São esses os elementos principais que constituem cada território formado historicamente por edificações e relações econômicas, políticas e culturais, além do homem (natureza-sociedade) e sua natureza exterior (MARX, 1984).

Por isso, entendemos o território em três níveis correlatos, separáveis apenas para fins didáticos: a) como conceito de orientação teórico-metodológica (na pesquisa, 
na extensão e no ensino), juntamente com outros conceitos basilares da Geografia: espaço, paisagem, região e lugar; b) como componente da realidade objetiva-subjetiva e, assim, objeto de estudos e de ensino-aprendizagem; c) como espaço de organização política, mobilização, luta e atuação em programas e projetos de desenvolvimento.

Neste texto, trabalharemos os dois primeiros níveis, ou seja, o território como conceito e processo social que precisa ser compreendido de maneira histórico-crítica, relacional, reticular e múltipla, e ensinado nos anos iniciais com a participação continuada, dialógica e criativa dos educadores e educandos. Identificar, entender e explicar os terriórios é um exercício fundamental e pode ser feito nos diferentes níveis de escolaridade [para referência geral sobre os tipos de território, ver Fernandes (2009)]. O mesmo ocorre com a problemática do ensino-aprendizagem, como pode ser observado em Sposito (2006).

Somente conseguimos identificar os territórios e as territorialidades quando estamos preparados para tal, isto é, precisamos ter clareza da abordagem que pretendemos fazer na pesquisa e durante as diferentes fases e momentos do ensinoaprendizagem. A abordagem e as concepções devem orientar nossas escolhas literárias, os estudos e a prática pedagógica; escolhas que precisam ser constantemente revistas, avaliadas e atualizadas.

\section{O território no processo ensino-aprendizagem}

Analisando algumas coleções de Geografia utilizadas no Ensino Fundamental identificamos, de maneira geral, duas situações predominantes referentes ao território e à territorialidade: a) no ensino do $1^{\circ}$. ao $4^{\circ}$. ano, o território é entendido em nível da família, no qual o estudante é motivado a se identificar. Tal questão é trabalhada juntamente com os conceitos de paisagem e/ou lugar; b) nos livros do $5^{\circ}$. ao $8^{\circ}$. ano, a ênfase é dada à atuação do Estado e ao trabalho por meio de diferentes situações da vida cotidiana. O estudante identifica as situações, auxiliado pelo professor e pelos pais, destacando relações econômicas e políticas. É uma concepção mais ampla de Geografia e território que tende a evidenciar as relações sociais, especialmente as de poder.

Conforme mencionamos anteriormente, para aprofundamento, definimos analisar uma coleção, evidenciando os conteúdos principais de cada livro $\left(1^{\circ}\right.$. ao $4^{\text {o }}$. ano), as atividades previstas, a concepção de Geografia e os conceitos trabalhados. 
Na coleção organizada por Sene, Cavalcanti e Moreira (2004), observamos uma subdivisão, em cada livro, em três unidades, além da Apresentação, Estrutura da obra e Sumário. No livro do $1^{\circ}$. ano, constam duas unidades que problematizam a vida estudantil na escola, sua organização interna e a sala de aula. Na terceira unidade, destacam-se a casa, a família dos estudantes e outras famílias. O conceito principal utilizado e trabalhado é o de lugar, efetivado a partir do sujeito-estudante.

É importante notar que, no Manual do Professor, que faz parte da coleção, mais precisamente na Carta aos professores, consta:

Nosso objetivo maior foi o de produzir uma coleção pautada na concepção de educação que respeite o aluno, acima de tudo, como indivíduo. (...) Buscamos oferecer um material com uma estrutura diferente, na qual professores e alunos possam interagir de maneira mais participativa e exploratória (...). (2004, p. 3).

A seguir, na Proposta teórico-metodológica da coleção, afirma-se:

Partimos do princípio de que a aprendizagem é fruto de uma construção pessoal, possuindo um caráter ativo, no qual intervém o sujeito que aprende e os outros que estão à sua volta. (...) Estamos assumindo nesta coleção que aprender possui um caráter dinâmico (...). Dessa forma, o ensino de geografia constitui-se num conjunto de atividades sistemáticas, cuidadosamente planejadas, em torno das quais conteúdo e forma de ensinar se articulam para que professor e aluno compartilhem parcelas cada vez maiores de significados. Isto é, o professor prepara suas ações de ensino para que o aluno participe de atividades que o façam se aproximar cada vez mais dos conteúdos da geografia. (2004, p. 9).

Há, na coleção, uma proposta de ensino-aprendizagem construtivista que aparece claramente também nas referências consultadas e indicadas ao professor, na organização interna de cada livro por meio dos textos, dos autores utilizados, das atividades, dos exercícios e das ilustrações.

No livro do $2^{\circ}$. ano, inicialmente, retoma-se o estudo da sala de aula, da escola e de seus arredores bem como do lugar de moradia dos educandos, as ruas e os bairros. Há destaque, na terceira unidade temática, para as relações entre as pessoas (famílias e vizinhos). Novamente, evidencia-se o estudante, a unidade de congregação - a família e o conceito de lugar, compreendido como um espaço de identidade com relações afetivas e simbólicas.

O lugar permanece o conceito principal da abordagem proposta e concretizada por meio dos textos e atividades que constam no livro do $3^{\circ}$. ano da coleção em questão. No entanto, notamos uma ampliação da escala de abordagem, para além da escola e do 
bairro, envolvendo a vida na cidade e no campo bem como as relações que acontecem entre os espaços urbano e rural. A vida urbana ganha destaque juntamente com as mudanças e os impactos provocados no ambiente em nível municipal. Dessa maneira, retoma-se o conceito de paisagem na coleção e destacam-se os elementos da natureza: o rio, o clima, as chuvas e o relevo. Na terceira unidade trabalham-se as noções de orientação cartográfica.

No último livro da coleção, contemplam-se aspectos da relação sociedadenatureza, os recursos da Terra, alguns problemas sociais do Brasil e a circulação de pessoas, produtos e informações. A ênfase, nas duas unidades iniciais, é para a problemática ambiental e para a comunicação e circulação. Na última unidade do livro, retoma-se o estudo da natureza (rios, climas, vegetações) e da degradação do ambiente no Brasil. Percebemos também um reforço por parte dos autores da coleção em relação ao aspecto cidadania no ensino de Geografia, realizado, no $4^{\circ}$. ano, a partir da problemática ambiental.

Ainda em relação aos livros da coleção, notamos coerência e integração entre os temas estudados em cada unidade do livro do $1^{\circ}$. ano, contemplando uma complexidade crescente a partir de aspectos da vida dos educandos, passando pela escola, seus espaços e profissionais, até a casa e a família dos estudantes e de outras pessoas. Os conteúdos estão bem articulados. Os textos usados, os exercícios, as atividades, as ilustrações e os diálogos propostos estão em consonância com cada unidade temática, propiciando a leitura, a observação, a comparação e a descrição por parte do educando, enfim, a compreensão de aspectos da sua vida diária e do lugar. A linguagem cartográfica, que tem centralidade na coleção, é trabalhada de forma coerente no livro do $1^{\circ}$. ano.

No livro do $2^{\circ}$. ano, é retomado o estudo da escola e das moradias, considerando as paisagens do bairro e de outros lugares, além de algumas relações familiares e com as famílias vizinhas. Dessa forma, verificamos uma continuidade dos conteúdos trabalhados no $1^{\circ}$. ano. Há coerência e articulação entre os temas estudados em cada unidade, contemplando uma complexidade crescente a partir da sala de aula e da escola, passando pela rua e pelo bairro até as relações de vizinhança e distintas profissões, ocorrendo uma espécie de fechamento ao primeiro ciclo de estudos. Os textos usados, os exercícios, as atividades, as ilustrações e os diálogos propostos 
também estão de acordo com cada unidade, propiciando o desenvolvimento de diferentes habilidades e a compreensão de aspectos do lugar de vida, da paisagem e das relações multiescalares (em nível municipal). A linguagem cartográfica também é trabalhada de forma coerente no livro do $2^{\circ}$. ano.

No livro do $3^{\circ}$. ano, também há oportunidades para estudar aspectos do lugar onde vivem os educandos e de outros lugares do Brasil, das relações que ocorrem entre os espaços urbano e rural, dos elementos da relação sociedade-natureza (clima, chuva, relevo), do processo histórico e das noções básicas de orientação cartográfica. Nesse livro, também há coerência entre os temas trabalhados em cada unidade a partir das características da vida dos educandos e da explicação de relações mais amplas em nível de município e país.

Há, nos textos do livro, elementos claros de uma concepção reticular do espaço geográfico. Os textos, os exercícios, as atividades, as ilustrações e os diálogos propostos estão em consonância com cada unidade temática e com os seus objetivos, propiciando o desenvolvimento de processos cognitivos básicos nos educandos, tais como a leitura, a observação, a comparação, a descrição, a reflexão e a pesquisa. Nesse livro, notamos a continuidade dos conteúdos do $2^{\circ}$. ano, retomando o estudo do lugar de moradia e trabalhando outros aspectos da construção do espaço geográfico. Percebemos, também, maior complexidade dos conteúdos nos textos do livro do $4^{\circ}$. ano, elaborados a partir das características da apropriação da natureza pela sociedade e das redes de circulação e comunicação. Também há coerência entre os temas estudados em cada unidade. O livro propicia uma continuidade em relação aos conteúdos estudados no $3^{\circ}$. ano, exceto no que se refere à unidade 3 daquele livro, na qual estudam-se noções de orientação e aspectos da vida das crianças, passando, no livro do $4^{\circ}$. ano, diretamente para a tematização dos problemas ambientais.

A estrutura basilar de cada livro é composta por ilustrações combinadas com textos, seguidas por atividades (questões, desenhos, jogos, brincadeiras, entrevistas, excursões, pesquisas, elaboração de materiais diversos, caça-palavras etc.) a serem realizadas pelos estudantes individualmente, em duplas e em grupos ou de forma coletiva (toda classe).

As atividades estão organizadas em três seções: a) "Quebra-cuca", presente nos quatro volumes da coleção com exercícios desafiadores que não podem ser indicados 
como tarefa de casa, porque exigem o acompanhamento mais direto do professor; $b$ ) "Leia, aprenda e divirta-se", em que são apresentadas sugestões literárias para o aprofundamento, revisão e ampliação da aprendizagem; c) "Lição de casa", presente apenas nos volumes do $3^{\circ}$. e $4^{\circ}$. anos, com atividades que retomam os assuntos tratados em sala de aula.

Outra constatação importante é que, nos livros do $1^{\circ}$. e $2^{\circ}$. anos, os textos são curtos, enquanto que nos do $3^{\circ}$. e $4^{\circ}$. anos, os textos são mais longos. Nos primeiros, priorizam-se as ilustrações e as atividades, que são diversificadas (brincadeiras, jogos, desenhos, pesquisas, dramatizações etc.) e, a partir delas, introduzem-se as informações, os conceitos e os textos complementares. Situações mais simples da vida escolar levam para outras mais complexas, de uma unidade temática para outra e de um ano para outro.

Notamos, por meio dos textos e, sobretudo, das atividades propostas, um esforço por parte dos autores da coleção para contribuir no desenvolvimento de conceitos da Geografia e de atitudes voltadas para a preservação do ambiente. Os textos, boxes, ilustrações, exercícios e atividades dos livros facilitam o desenvolvimento dos aspectos mencionados bem como o envolvimento e a participação dos educandos nas aulas. Assim, há valorização dos conhecimentos prévios dos estudantes, os temas abordados são relacionados com a realidade vivenciada pelas crianças estimulando-se a participação nos problemas que envolvem a comunidade.

A partir de situações da realidade vivenciada pelos educandos, abordam-se os conteúdos introduzindo os conceitos de lugar, paisagem, espaço e território, além das noções de campo e cidade. Nos livros de $1^{\circ}$. e $2^{\circ}$. anos, o conceito principal é o de lugar, compreendido como formas, construções e relações sociais, interagido com o de espaço geográfico. No $3^{\circ}$. ano, há ênfase para os conceitos de espaço geográfico (por meio das relações que ocorrem entre os espaços urbano e rural, dos impactos provocados no meio ambiente e dos elementos da natureza, tais como clima, água e relevo) e lugar, considerando-se também os de paisagem e território, como ocorre no livro do $4^{\mathrm{o}}$. ano.

Um dos limites da coleção, porém, está presente ao estudar os elementos da natureza. Estes são apresentados apenas como recursos para a sociedade. Não é trabalhado o caráter processual da natureza nem seu significado-importância como patrimônio da humanidade. Esse é um limite da abordagem elaborada pelos autores, 
apesar de ter sido bem trabalhada na coleção. Há conteúdos e situações, em cada livro, que propiciam uma visão crítica por parte do estudante.

No volume do $4^{\circ}$. ano, por exemplo, a abordagem da natureza como recurso para a sociedade fica evidenciada, iniciando-se a Unidade I com o tema da apropriação da natureza pela sociedade. Assim, enfoca-se a transformação dos minerais, os recursos naturais renováveis, os não-renováveis e os limites da natureza como recursos naturais, destacando-se a utilização da água no planeta. Na Unidade III - A natureza e as agressões ambientais, trabalham-se, de forma superficial, as relações entre os elementos da natureza (relevos, rios, climas e vegetações).

Outro limite da abordagem proposta, no livro do $2^{\circ}$. ano, está na utilização do conceito de zona, pois implica, necessariamente, uma compreensão areal do espaço e do território, indicando uniformidade e não a apreensão das desigualdades, das diferenças, dos processos históricos e das relações sociais. Essa é uma contradição, pois há, na coleção, várias possibilidades para o entendimento das relações espaciotemporais, isto é, de aspectos da formação histórica do espaço geográfico, que poderiam ser trabalhados de modo um pouco diferente. Há ênfase, por exemplo, na identificação de algumas mudanças e alguns agentes sociais organizadores e construtores do espaço geográfico e do lugar, o que possibilita a compreensão de que a sociedade, conforme suas necessidades e interesses, modifica o espaço e o lugar, alterando e degradando historicamente a natureza exterior ao homem.

Apesar desses limites que existem na obra em questão, os conceitos de lugar, espaço geográfico e paisagem estão corretos. Já o conceito de território é concebido e trabalhado de forma incompleta e superficial, restrito à formação do Brasil, como área com características específicas (população, relevo, rios, clima, vegetação etc.), ou seja, como Estado-Nação, o que é limitado diante dos debates, das pesquisas e das publicações que existem sobre esse conceito no Brasil, apontando para abordagens renovadas, atualizadas e mais amplas. Consoante Freire (2011/1996), ensinar exige risco e aceitação do novo, numa construção dialógica e responsável do conhecimento. “O respeito à autonomia e à dignidade de cada um é um imperativo ético e não um favor que podemos ou não conceder uns aos outros" (FREIRE, 2011/1996, p. 58).

As relações sociais e interações ambientais, ambas espaciotemporais, por exemplo, trabalhadas ao longo da coleção, não são relacionadas ou identificadas como 
inerentes à constituição do território, mas sim ao espaço geográfico e ao lugar. Isso é um problema? Não, evidentemente, pois se trata de uma das interpretações possíveis e deve ser respeitada como a opção principal dos autores da coleção. Porém, as diversas situações ao longo dos textos, dos exercícios e das atividades podem ser "exploradas" com a finalidade de explicar outros aspectos relativos a cada tema, tais como as relações de poder que extrapolam a atuação do Estado, as redes-conexões e as identidades simbólico-culturais estabelecidas fora do âmbito das famílias.

Não se trata, obviamente, de desprestigiar conceitos importantes como lugar e espaço geográfico. O que pode ser feito é uma abordagem mais completa e adequada dos processos históricos e das relações cotidianas, mesmo nos anos iniciais, introduzindo de maneira mais ampla e profunda conceitos como território e territorialidade.

Sucintamente, o conceito de lugar é fruto das produções (edificações) e das relações sociais efetivadas na vida dos educandos e das outras pessoas, e o espaço geográfico, das interações, historicamente condicionadas, que existem entre os elementos da natureza e entre a sociedade e a natureza. O lugar e o espaço contêm a natureza exterior ao homem e as relações sociais. O primeiro diferencia-se do segundo basicamente por compreender relações afetivas e de identidade (na casa, na rua e no bairro onde o estudante mora, na escola onde estuda, nas brincadeiras etc.), conforme normalmente ocorre quando se conceitua o lugar. Notamos isso no livro do $3^{\circ}$. ano, por exemplo, nas atividades da p.15: "2. No lugar onde vocês moram existem espaços para programações culturais, esportivas e de lazer voltadas para crianças e jovens? Se existem, cite exemplos (...). 4. Pense novamente no que deveria mudar para melhorar a vida das crianças que moram e circulam nesse lugar (...)".

Já espaço geográfico é o conceito mais amplo e corresponde, na coleção em questão, à principal categoria da análise geográfica. O território consta como conceito subjacente, o que dificulta a explicação e compreensão dos aspectos já mencionados a partir dos temas de cada unidade dos livros da coleção. Isso dificulta, evidentemente, a construção, com os educandos, de uma leitura mais ampla, crítica e coerente dos processos sociais e territoriais, sem invalidar ou desprestigiar a qualidade da coleção.

Detalhando nossa análise, percebemos que, no livro do $1^{\circ}$. ano, entre as p. $56 \mathrm{e}$ 59, os conceitos de espaço e lugar são trabalhados corretamente, por meio de temas da 
escola, do Brasil e do mundo. A atividade da p. 103 ("Você sabe qual a origem de seu sobrenome? É de origem portuguesa, italiana, alemã, japonesa, árabe etc.?”), por exemplo, possibilita o estudo de aspectos culturais da história das famílias e dos lugares de vida. Porém, o tema não está relacionado com a mobilidade populacional inerente à formação de cada família e à sua territorialização, processo que pode ser trabalhado nos anos iniciais.

Algo semelhante ocorre no livro do $2^{\circ}$. ano: nas atividades da p. 23 , os conceitos de espaço, sociedade e natureza são trabalhados adequadamente; o conceito de lugar está correto, por exemplo, na p. 47, ao se problematizar o estudo da rua de moradia dos alunos através da identificação de edificações e relações sociais, diferenças e usos. No entanto, não se relaciona essa discussão com o território de vida dos educandos, enfim, com o arranjo territorial do bairro, com as relações de influência e com os conflitos que acontecem entre os vizinhos e na própria família. Contraditoriamente, nas p. 45 e 47, evoca-se, incoerentemente o conceito de zona, consoante já mencionamos.

Já o conceito de paisagem está bem trabalhado, por exemplo, na atividade da p. 55: “Observando paisagens", e na p. 61, entendido como fruto dos elementos naturais e dos componentes construídos pelas pessoas. A paisagem contém características naturais e sociais, e isto é muito coerente, pois possibilita o estudo das paisagens do bairro e de outros lugares. A paisagem é bastante utilizada no decorrer das unidades dos livros da coleção, por meio das ilustrações, possivelmente por serem entendidas como uma forma de envolver os educandos nas aulas e por facilitar a compreensão a partir da imagem.

Notamos uma complexidade maior nos textos e atividades dos livros dos $3^{\circ}$. e $4^{\circ}$. anos: no primeiro, enfatizam-se as diferenças entre as paisagens, os lugares e a relação com o ambiente, identificando-se mudanças sociais e impactos, ou seja, os elementos da natureza e as transformações nela provocadas nos bairros industriais e centros comerciais. No segundo, também se evidencia a apropriação da natureza pela sociedade e alguns problemas sociais do Brasil, como processos que fazem parte da construção do espaço geográfico.

Há, em todos os livros, uma quantidade satisfatória de exercícios, textos, ilustrações e atividades que propiciam ao educando a comparação, a observação, o debate, a análise e a reflexão, combinando informações do senso comum e do nível 
científico de produção do conhecimento. São propostas atividades diversificadas: redação de textos, observação e leitura de ilustrações, de dados e documentos, discussão, elaboração de materiais diversos, brincadeiras, desenhos e pesquisas que estimulam a análise e o estabelecimento de relações pelo estudante, seja de forma individual, em dupla ou coletivamente.

Essa qualidade presente nos livros pode ser ampliada pelo educador, em conjunto com os estudantes e outros sujeitos que podem ser convidados a participar do processo ensino-aprendizagem, estimulando as interações que extrapolam os limites da sala de aula e o desenvolvimento de diversas habilidades, tais como observar, comparar, classificar, analisar, sistematizar, representar e pesquisar. Para tal, parece-nos fundamental a utilização do conceito de território e de suas derivações: territorialidade, desterritorialização e reterritorialização.

Didaticamente, para cada ano, é possível "explorar" mais determinados aspectos da formação territorial. No $1^{\circ}$. e no $2^{\circ}$. ano, é pertinente trabalhar a relação lugar-identidade-território ou ainda paisagem-território. Para tanto, não é necessário escrever um novo livro didático. Basta que o professor esteja atento e atualizado, potencializando os textos, as atividades, as ilustrações etc. dessa coleção, por exemplo, ampliando durante o ano letivo o nível de análise com as crianças. Os textos, as ilustrações, os boxes, as sugestões de leitura e as atividades (como as entrevistas), estão bem distribuídas na coleção, propiciando oportunidades para que o educando possa pensar, comparar, representar e questionar sobre sua vida diária, os temas da Geografia e a problemática que envolve o território numa perspectiva histórico-crítica, relacional, reticular e multidimensional (RAFFESTIN, 1993; DEMATTEIS, 1985 e 1995; SAQUET, 2003/2001, 2007 e 2011) ou pluridimensional (DANSERO e ZOBEL, 2007) como estamos assumindo atualmente.

A partir dos textos, das atividades e dos exercícios do livro do $1^{\circ}$. ano, sobre a vida estudantil na escola, a casa e a família dos estudantes e de outras famílias, pode-se trabalhar, além das relações afetivas e simbólicas, com informações conflituosas que fazem parte desses lugares, tais como as rixas de sala de aula e das brincadeiras, as diferentes etnias presentes em cada família (hábitos alimentares, músicas, religiões etc.) e a hierarquia interna existente na escola: estudantes, professores, funcionários, 
diretores, supervisores etc. Na identidade cultural também há heterogeneidade, disputas e luta de classes (THOMPSON, 1998; FREIRE, 2011/1996; SAQUET, 2003/2001).

Uma explicação dessa organização escolar histórica e socialmente instituída para as crianças e um "passeio" orientado pelas dependências da escola auxiliará na problematização para o entendimento de detalhes da construção territorial que, muitas vezes, passam despercebidos das crianças e de muitos professores. "Não há ensino sem pesquisa e pesquisa sem ensino" (FREIRE, 2011/1996, p. 30).

A partir da temática central trabalhada no livro do $2^{\circ}$. ano, ou seja, das relações entre as pessoas-bairro-lugar destacando as características identitárias e culturais, também é possível problematizar, ampliar e aprofundar a discussão com as crianças a partir de uma "caminhada" na escola e no bairro, mostrando e explicando as diferenças e as desigualdades; a organização política dos moradores (quando existe, por exemplo, através das associações de bairro ou de agricultores); as características do relevo, do solo, da vegetação e as alterações provocadas pela organização social das casas, lotes/terrenos, edifícios, ruas, estradas, plantações, dutos, pontes etc. como implicações do homem-sociedade na sua natureza exterior num movimento mais amplo de territorialização nos termos indicados por Raffestin (1984, 1993, 2003 e 2009). As crianças, ao retornar para a sala de aula, podem desenhar o que viram e apresentar para os colegas da turma e/ou para os demais estudantes da escola, discutindo os conteúdos explicados pelo professor.

Por isso mesmo pensar certo coloca ao professor ou, mais amplamente, à escola, o dever de não só respeitar os saberes com que os educandos, sobretudo os das classes populares, chegam a ela - saberes socialmente construídos na prática comunitária -, mas também, (...) discutir com os alunos a razão de ser de alguns desses saberes em relação com o ensino dos conteúdos. (FREIRE, 2011/1996, p. 31).

São atividades simples e conhecidas dos professores em geral, porém, precisam ser trabalhadas oportunamente de acordo com cada tema, ano, com os objetivos das aulas, enfim, com cada situação específica do ensino-aprendizagem. O professor precisa ter sensibilidade para escolher as atividades adequadas para sua prática pedagógica dentro e fora da sala de aula como mediação para problematizar, sensibilizar, discutir e compreender. Estes, por sua vez, precisam formar suas próprias opiniões a partir dos desafios lançados pelo professor. 
Nos $1^{\circ}$. e $2^{\circ}$. anos, também é possível trabalhar detalhes da organização política convidando alguma liderança da sociedade local para falar para os estudantes. Isso pode ser feito por uma pessoa da associação de moradores ou da paróquia, por exemplo, evidenciando traços comuns/identitários presentes nessas instituições: são territorialidades que condicionam a produção territorial (RAFFESTIN, 1993 e 2009; SAQUET, 2011) dos bairros e das "comunidades" rurais, numa relação mais ampla que envolve a unidade território-lugar. A relação paisagem-território pode ser profícua da mesma forma, mostrando e explicando características da interferência social nos loteamentos urbanos, nas hortas (da própria escola, quando houver), nos pomares, nas praças etc. Há paisagens urbanas e rurais, transformadas e não transformadas socialmente; elas resultam da formação de cada território e contêm componentes naturais e sociais (materiais-imateriais) facilmente demonstráveis e explicáveis por meio das situações cotidianas das crianças.

Nos $3^{\circ}$. e $4^{\circ}$. anos, é possível trabalhar com a relação espaço-território ou lugarpaisagem-território além do que já consta em cada livro, tornando o estudo dos temas de Geografia ainda mais complexos. Selecionamos algumas situações do livro do $3^{\circ}$. ano: a atividade e as ilustrações da p. 23 propiciam uma boa oportunidade para o debate das relações que acontecem entre a sociedade e a natureza e das diferentes paisagens e construções feitas no espaço geográfico; isso é ratificado com as atividades da p. 24: “4. Quais foram os elementos da natureza que você mais gostou ao observar as paisagens das fotografias? 5. Quais foram os elementos construídos pela sociedade que mais chamaram a atenção?” Identificam-se também as diferenças entre as paisagens naturais, como as florestas e as geleiras polares, onde há predomínio dos elementos da natureza, mas não se abordam os processos e/ou dinâmicas que lhes são próprios nem as diferenças sociais (econômicas, políticas e culturais) entre os grupos indígenas que habitam as florestas, por exemplo. Nas tribos indígenas há identidades, mobilidade espacial, conflitos e poder, aspectos que, normalmente, são vinculados aos conceitos de território e lugar. Há também águas, plantas, animais, ocas, tabas etc. que se objetivam nas paisagens.

Entre as p. 63 e 76, enfocam-se os elementos da natureza no cotidiano das pessoas, como o clima, as variações de temperatura, as chuvas e o relevo, a ocupação humana dos morros e as conseqüências das inundações. Entretanto, não se trabalha com 
o processo de urbanização direcionado por agentes públicos e privados, envolvendo relações de poder e interesses econômicos específicos. Isso auxiliaria na formação de uma consciência política nas crianças, por meio de situações simples e peculiares à vida cotidiana. É possível organizar a coleta de reportagens em jornais locais sobre a especulação imobiliária explicando as características da natureza exterior ao homem, as intervenções do homem, as instituições responsáveis e seus interesses, e os distintos sujeitos que dinamizam a reconstrução incessante dos territórios.

A partir da problemática da ocupação humana, é importante trabalhar também as desigualdades internas de uma cidade, entre as classes, os grupos sociais e a materialização disso nos bairros nobres, de periferia e nas favelas. É uma temática complexa, todavia as crianças do $3^{\circ}$. e do $4^{\circ}$. ano já têm condições psicológicas para entender as características dessa territorialização, que também acontece no espaço rural. Os educandos podem coletar figuras de reportagens e fotografar a cidade e o espaço rural, construindo painéis temáticos, apresentando-os e debatendo-os com a participação/mediação do educador. É instigante trabalhar, ao mesmo tempo, com as desigualdades e diferenças entre famílias, bairros e comunidades rurais, juntamente com as respectivas territorialidades exercidas entre as pessoas no ambiente. É necessário que todos os envolvidos na prática pedagógica assumam-se como seres sociais, históricos, pensantes, criadores, transformadores, comunicantes (FREIRE, 2011/1996), que se relacionam dialeticamente com sua natureza exterior.

As crianças do $4^{\mathrm{o}}$. ano normalmente têm condições de compreender aspectos da organização social em diferentes níveis, como o da família, da escola, da cidade, da relação campo-cidade, do município e do Estado inserido em redes internacionais. É possível trabalhar, assim, a importância das redes em cada formação territorial por meio da problemática da comunicação e da circulação (telefone, rádio, tv, internet, rodovias, estradas, ruas etc.). A rede também pode ser estudada a partir do tema bacia hidrográfica, partidos políticos, agências de correios e assim por diante. Há múltiplas possibilidades e situações para cada turma, ano, escola, lugar, tempo e território. A própria sala de aula pode ser estudada, compreendida e explicada como um lugar e como um território. Todas as possibilidades podem, de diferentes maneiras, ser potencializadas para romper com a concepção de zona e de natureza como recurso para a sociedade. 
É fundamental, no processo ensino-aprendizagem, em todos os níveis, dentro e fora da sala de aula, construir uma consciência da natureza como nosso patrimônio. Patrimônio que está nas plantas, nos animais, nas rochas, nos rios, em nossos corpos. Patrimônio que está nos costumes, nas crenças, nas línguas, nas músicas, nas escolas, no campo, na cidade, em cada lugar, paisagem, território, enfim, na vida e, por isso, precisa ser estudado, compreendido e explicado da melhor maneira possível, para que possamos juntos construir uma sociedade mais justa e menos degradante. “(...) Transformar a realidade opressora é tarefa histórica, é tarefa dos homens" (FREIRE, 2011/1974, p. $51)$.

\section{Considerações finais}

Ensinar e aprender são dois processos inseparáveis na escola e fora dela. Nela, o livro didático assumiu centralidade e, assim, precisa ter qualidade e ser utilizado criativamente. Evidentemente, o educador necessita, em qualquer nível de ensinoaprendizagem, planejar e elaborar outras estratégias, atividades e outros procedimentos didáticos, isso exige investimento de tempo e de recursos financeiros, domínio dos conteúdos e das práticas pedagógicas.

Nesse sentido, a abordagem territorial possibilita a ampliação da compreensão dos temas e das análises problematizadas no livro didático. Uma abordagem crítica, múltipla, histórica, relacional e reticular é necessária como orientação teóricometodológica para a pesquisa e para o processo ensino-aprendizagem de Geografia. Ensino-aprendizagem centrado na mediação do professor, no reconhecimento e na valorização dos saberes dos estudantes, portanto, numa práxis dialógica, nos termos em que argumentamos em Saquet (2011). "De nada serve, a não ser para irritar o educando e desmoralizar o discurso hipócrita do educador, falar em democracia e liberdade, mas impor ao educando a vontade arrogante do mestre" (FREIRE, 2011/1996, p. 61).

Essa é uma das formas de compreensão e explicação da nossa vida, dos processos e interações que vivemos todos os dias. Assim, a escola corresponde a um território num contexto de relações de poder, redes, identidades, diferenças, conflitos e lutas de classe.

Por isso, é preciso entender e trabalhar também as relações que se estabelecem a partir da escola, envolvendo os educandos, os pais, as demais famílias, os membros da 
sociedade local, os agricultores, os operários etc., dependendo dos temas abordados dentro e fora da sala de aula. Há um território da escola que precisa ser identificado, compreendido, valorizado e potencializado para o processo ensino-aprendizagem de Geografia.

Assim, é fundamental uma forma criativa e dinâmica de organização dos conteúdos dos livros didáticos para tornar o ensino-aprendizagem nos anos iniciais do Ensino Fundamental, um processo agradável aos professores e educandos. O docente precisa estar bem preparado, atualizado, motivado e disposto a encarar e superar os desafios cotidianos presentes em qualquer nível de ensino e escola.

O território na escola constitui, sem dúvidas, um ótimo tema para compreender e explicar aspectos fundamentais da sociedade e da natureza em que vivemos. O universal está no singular e, este, naquele (LEFEBVRE, 1995; SANTOS, 1996; SAQUET, 2003/2001). Conforme nossa pesquisa demonstrou, a coleção analisada tem várias qualidades e oportuniza a realização de atividades coerentes com os anos do ensino fundamental.

Há adequação entre a metodologia de ensino-aprendizagem proposta no Manual do Professor da coleção e a sua aplicação nos livros, e entre a fundamentação teórico-metodológica da Geografia proposta e a utilizada, facilitando o processo de aprendizagem de Geografia. Os textos, boxes, ilustrações, exercícios e atividades dos livros propiciam o envolvimento e participação do aluno, o desenvolvimento de conceitos, procedimentos e atitudes para a interação na vida social, enfim, a construção crítica do conhecimento geográfico. Há, na organização dos conteúdos dos diferentes livros, uma preocupação com a complexidade crescente na aprendizagem de Geografia, possibilitando a compreensão de relações sociais, de interações ambientais e transformações históricas na construção do espaço geográfico. A coleção também contempla distintos estímulos ao desenvolvimento dos processos cognitivos básicos que contribuem na aprendizagem e na formação do cidadão, como observação, memorização, comparação, classificação, compreensão, interpretação, análise, investigação, generalização, criatividade, problematização, síntese e formulação de hipóteses.

Assim, há valorização dos conhecimentos prévios das crianças bem como preocupação em relacionar os temas abordados com a realidade vivenciada pelas 
mesmas. Isso não significa, evidentemente, que não se pode qualificar o ensinoaprendizagem feito a partir do livro didático. Sempre há outras possibilidades, consoante tentamos mostrar na segunda parte deste texto tecendo sugestões para complementar a concepção trabalhada na coleção e as atividades propostas.

\section{REFERÊNCIAS}

DANSERO, Egidio e ZOBEL, B. Verso un dialogo tra comunità scientifica e comunità locale. In: Promozione della sostenibilità nel Pinerolese - un percorso di ricerca/azione territoriale. Turim: Euro Mountains, 2007. p. 135-141.

DEMATTEIS, Giuseppe. Le metafore della terra. La geografia umana tra mito e scienza. Milano: Feltrinelli, 1985.

DEMATTEIS, Giuseppe. Progetto implicito. Il contributo della geografia umana alle scienze del territorio. Milano: Angeli, 1995.

FERNANDES, Bernardo. Sobre a tipologia de territórios. In: SAQUET, M. e SPOSITO, E. (Org.). Territórios e territorialidades: teorias, processos e conflitos. São Paulo: Expressão Popular, 2009. p. 197-215.

FREIRE, Paulo. Pedagogia do oprimido. São Paulo: Paz e Terra, 2011/1974.

FREIRE, Paulo. Pedagogia da autonomia - saberes necessários à prática educativa. São Paulo: Paz e Terra, 2011/1996.

LEFEBVRE, Henri. Lógica formal/lógica dialética. Rio de Janeiro: Civilização Brasileira, 1995.

MARX, Karl: Manuscritos: economia y filosofia. Traducción, introducción y notas de Francisco R. Llorente. Madrid: Alianza Editorial, 1984.

RAFFESTIN, Claude. Territorializzazione, deterritorializzazione, riterritorializzazione e informazione. In: TURCO, A. (Org.). Regione e regionalizzazione. Milano: Angeli, 1984. p. 69-82.

RAFFESTIN, Claude. Por uma geografia do poder. São Paulo: Ática, 1993.

RAFFESTIN, Claude. Immagini e identità territoriali. In: DEMATTEIS, G. e FERLAINO, F. (Orgs.). Il mondo e i luoghi: geografie delle identità e del cambiamento. Torino: IRES, 2003. p. 3-11.

RAFFESTIN, Claude. A produção das estruturas territoriais e sua representação. In: SAQUET, M. e SPOSITO, E. (Org.). Territórios e territorialidades: teorias, processos e conflitos. São Paulo: Expressão Popular, 2009. p. 17-35.

SANTOS, Milton. A natureza do espaço. Técnica e tempo. Razão e Emoção. São Paulo: Hucitec, 1996.

SAQUET, Marcos. Os tempos e os territórios da colonização italiana. Porto Alegre: EST Edições, 2003/2001.

SAQUET, Marcos. Abordagens e concepções de território. São Paulo: Expressão Popular, 2007.

SAQUET, Marcos. Por uma abordagem territorial. In: SAQUET, M. e SPOSITO, E.

(Org.). Territórios e territorialidades: teorias, processos e conflitos. São Paulo: Expressão Popular, 2009. p. 73-94. 
SAQUET, Marcos. Por uma geografia das territorialidades e das temporalidades: uma concepção multidimensional voltada para a cooperação e para o desenvolvimento territorial. São Paulo: Outras Expressões, 2011.

SENE, E. de, CAVALCANTI, C., MOREIRA, J. C. Geografia PARATODOS (vol. 1, 2, 3 e 4). São Paulo: Scipione, 2004. (Coleção Paratodos).

SPOSITO, Maria E. B. (Org.). Livros didáticos de História e Geografia: avaliação e pesquisa. São Paulo: Cultura Acadêmica, 2006.

THOMPSON, Edward. Costumes em comum: estudos sobre a cultura popular tradicional. São Paulo: Cia das Letras, 1998.

Artigo encaminhado para publicação em novembro de 2012.

Artigo aceito para publicação em novembro de 2012. 